\title{
The International Impact of the Active Healthy Kids Global Alliance Physical Activity Report Cards for Children and Youth
}

\author{
Salomé Aubert, Joel D. Barnes, Megan L. Forse, Evan Turner, Silvia A. González, Jakub Kalinowski, \\ Peter T. Katzmarzyk, Eun-Young Lee, Reginald Ocansey, John J. Reilly, Natasha Schranz, \\ Leigh M. Vanderloo, and Mark S. Tremblay
}

\begin{abstract}
Background: In response to growing concerns over high levels of physical inactivity among young people, the Active Healthy Kids Global Alliance developed a series of national Report Cards on physical activity for children and youth to advocate for the promotion of physical activity. This article provides updated evidence of the impact of the Report Cards on powering the movement to get children and youth moving globally. Methods: This assessment was performed using quantitative and qualitative sources of information, including surveys, peer-reviewed publications, e-mails, gray literature, and other sources. Results: Although it is still too early to observe a positive change in physical activity levels among children and youth, an impact on raising awareness and capacity building in the national and international scientific community, disseminating information to the general population and stakeholders, and on powering the movement to get kids moving has been observed. Conclusions: It is hoped that the Report Card activities will initiate a measurable shift in the physical activity levels of children and contribute to achieving the 4 strategic objectives of the World Health Organization Global Action Plan as follows: creating an active society, creating active environments, creating active lives, and creating active systems.
\end{abstract}

Keywords: global comparisons, sedentary behavior, health promotion, sport, evaluation, policy

Physical inactivity is a leading risk factor for global mortality in adults, along with high blood pressure, tobacco use, and high blood glucose, ${ }^{1}$ and was estimated to be responsible for at least $9 \%$ of premature mortality or more than 5.3 million deaths worldwide in $2008 .^{2}$ In addition, it was estimated to cause at least $6 \%$ of the burden associated with coronary heart disease, $7 \%$ of type 2 diabetes, $10 \%$ of breast cancer, and $10 \%$ of colon cancer. ${ }^{2}$ Based on these statistics, physical inactivity is described as one of "the biggest public health problems of the 21st century." 3,4 The most recent global prevalence of physical inactivity (ie, not meeting physical activity guidelines) was estimated to be $27.5 \%$ for adults ( $\geq 18$-y-olds $)^{5}$ and $81 \%$ for youth (11- to 17 -y-olds). ${ }^{6}$ Given that physical activity habits in childhood tend to track into adulthood, ${ }^{7}$ a high prevalence of physical inactivity among youth is a pressing concern. In addition, an overall decrease in physical fitness levels ${ }^{8}$ and an increase in the global prevalence of obesity among 5- to 19-year-olds have been observed since 1975 in many world regions. ${ }^{9}$ This compelling evidence suggests that a significant increase in premature health issues can be anticipated if the global physical inactivity crisis is not addressed. ${ }^{10}$

Aubert, Barnes, Forse, Turner, González, and Tremblay are with Healthy Active Living and Obesity Research Group, CHEO Research Institute, Ottawa, ON, Canada. González is also with the School of Medicine, Universidad de los Andes, Bogotá, Colombia. Kalinowski is with V4SPORT Foundation, Wroclaw, Poland; and International Sport and Culture Association, Copenhagen, Denmark. Katzmarzyk is with Pennington Biomedical Research Center, Baton Rouge, LA, USA. Lee is with the School of Kinesiology and Health Studies, Queen's University, Kingston, ON, Canada. Ocansey is with the University of Ghana, Accra, Ghana. Reilly is with the Physical Activity for Health Group, University of Strathclyde, Glasgow, Scotland. Schranz is with the National Heart Foundation of Australia, Melbourne, VIC, Australia; and the School of Health Sciences, University of South Australia, Adelaide, SA, Australia. Vanderloo is with ParticipACTION, Toronto, ON, Canada. Tremblay (mtremblay@cheo.on.ca) is corresponding author.

\section{Background}

\section{Report Card of Physical Activity Grades}

In response to growing concerns over high levels of physical inactivity among young people in Canada, the Report Card on Physical Activity for Children and Youth was first created in 2005 by Active Healthy Kids Canada, a registered not-for-profit organization, to advocate for the promotion of physical activity in Canadian children and youth. ${ }^{11}$ A summary of the Report Card background and development process has been published elsewhere. ${ }^{12}$ The Report Card is a public-facing document that synthesizes the best available evidence on children's physical activity with the purpose of reporting letter grades, updating scientific information, highlighting research gaps, and providing recommendations for improvement on a number of physical activity indicators for children and youth. ${ }^{12}$

Designed to serve as a knowledge translation tool and to accelerate the dissemination of physical activity research and evidence-based practice, the Report Card has successfully contributed to the movement to help get children moving by influencing priorities, policies, and practices in Canada over a 10-year period. ${ }^{13}$ Although the release of this annual research synthesis has resulted in positive changes across several sources of influence indicators (ie, Family and Peers, School, Community and Environment, Government, Nongovernment) in Canada between 2005 and 2016, these changes have not resulted in any meaningful increase in the prevalence of children and youth meeting the recommended 60 minutes of moderate- to vigorous-intensity physical activity per day. ${ }^{14}$ In celebration of the 20th anniversary of Active Healthy Kids Canada and the 10th anniversary of the Report Card, Active Healthy Kids Canada organized the Global Summit on the Physical Activity of Children in Toronto, Canada, in 2014. ${ }^{15}$ The major highlight of the Global Summit was the collaboration among 15 countries that prepared and simultaneously released their respective country-specific Report Cards on physical activity for children and youth. ${ }^{11,15}$ 


\section{Internationalization of the Report Card: The Global Matrix of Physical Activity Grades}

In 2014, the Canadian Report Card process was replicated in 15 countries from 5 continents (Australia, Canada, Colombia, England, Finland, Ghana, Ireland, Kenya, Mexico, Mozambique, New Zealand, Nigeria, Scotland, South Africa, and United States) for the first time, thus constituting the Global Matrix 1.0. ${ }^{11}$ The Report Card and Global Matrix initiatives are deliberately integrated into the larger global context as summarized in Figure 1. All Report Cards were generated through a harmonized development process using 9 common physical activity indicators and a standardized grading framework ("F" = failing to "A" = excellent) as presented in Table $1 .{ }^{11}$ Grades for the 9 common indicators were grouped into 2 categories as follows: 5 behavioral indicators (Overall Physical Activity, Organized Sport and Physical Activity Participation, Active Play, Active Transportation, and Sedentary Behaviors) and 4 sources of influence indicators (Family and Peers, School, Community and Built Environment, and Government Strategies and Investment). ${ }^{11}$ The Global Matrix 1.0 was a successful pilot project, opening the door to harmonized international comparisons and identifying strengths, disparities, inequities, research and surveillance gaps, and highlighting that none of the participating countries had all of the solutions to effectively promote physical activity among children and youth. The Global Matrix 1.0 facilitated the cross-fertilization of innovative solutions for countries with low grades to learn from those with high grades in particular areas. For example, the Scotland Report Card team learned that in the countries with better grades in physical activity and sedentary behavior than Scotland, children were spending much more time in active outdoor play. ${ }^{16}$

Following the success of the 2014 Global Summit, the Active Healthy Kids Global Alliance (AHKGA) ${ }^{24}$ was established. In July 2014, the AHKGA distributed an open call through established networks for interested countries to participate in the Global Matrix 2.0 project. As a result, a $250 \%$ increase in the countries involved over the Global Matrix 1.0 was observed with the participation of 38 countries from 6 continents. ${ }^{16}$ The AHKGA organized the concurrent preparation of 38 Report Cards on the physical activity of children and youth and their aggregation, creating the Global Matrix 2.0 on Physical Activity of Children and Youth, which was released in Bangkok, Thailand, on November 26, 2016. Findings from the second iteration of this global report showed that no one country was leading or lagging in all indicators, but rather, each country was experiencing its own unique successes and challenges. ${ }^{16}$ The authors concluded that increasing physical activity opportunities for children and youth around the world remains unresolved, and tackling this challenge internationally through the Global Matrices has the potential to provide unique insights, motivation, and synergies that could not be achieved in isolation. ${ }^{16}$

In April 2017, the AHKGA invited countries that had previously developed report cards and called for new countries to register for the Global Matrix 3.0. Working groups from 49 countries from 6 continents followed the updated harmonized procedures to grade 10 common physical activity indicators (ie, Overall Physical Activity, Organized Sport and Physical Activity, Active Play, Active Transportation, Sedentary Behaviors, Physical Fitness, Family and Peers, School, Community and Environment, and Government) using the best available data to develop their Report Card between July 2017 and July 2018.23 Details about the amended Report Card development process and the new mentoring structure that were implemented for the Global Matrix 3.0 have been described elsewhere. ${ }^{23}$ During this time, the AHKGA officially became an incorporated not-for-profit organization to increase its leadership in advocating for the promotion of physical activity among children and youth of all ages, genders, and abilities. The Global Matrix 3.0 was released at the Movement to Move Event in Adelaide, Australia, on November 27, 2018.

\section{Objectives}

Between 2005 and 2017, 72 national Report Cards were developed and released, and an additional 49 national Report Cards, developed in 2017-2018, were presented in this supplemental issue of the Journal of Physical Activity and Health (volume 15, supplement 2, 2018). The development and release of the Report Cards and of the Global Matrix have potentially created some momentum toward the surveillance and the promotion of physical activity among children and youth. The objective of the present article is to update a previous article assessing the impact of the Active Healthy Kids Canada Report Cards, ${ }^{13}$ with a new focus on the international impact of the Report Cards and Global Matrices. To this end, the authors have reviewed a variety of information from published scientific and gray literature, surveys collected by institutions involved in the development of the Global Matrices or Report Cards, media summaries, minutes from the AHKGA executive meetings, and reports from Report Card working groups. This article aims to provide updated evidence of the multiple positive impacts of the Report Cards and Global Matrix initiatives on the international scientific community, on raising awareness among the general population and stakeholders, and on powering the movement to get children and youth moving globally.

\section{International Context of the Report Cards and Global Matrices}

In response to increasing noncommunicable diseases related to physical inactivity among individuals of all ages, international calls for action were distributed by major global health institutions including the United Nations, ${ }^{19,25}$ the World Health Organization, ${ }^{22}$ and the Global Advocacy for Physical Activity group. ${ }^{26}$ The international context of the Report Cards and Global Matrices is summarized in Figure 1, showing that these initiatives aligned with, and supported, a global movement toward the surveillance and promotion of physical activity.

The Report Cards and the Global Matrices are guided by 3 principles from the Toronto Charter as follows: building capacity and supporting training in research, practice, policy, evaluation, and surveillance (guiding principle 5); addressing environmental, social, and individual determinants of physical inactivity (guiding principle 3); and ensuring cultural sensitivity and adapting strategies to accommodate various "local realities," contexts, and resources (guiding principle 8). ${ }^{27}$ The Global Matrix constitutes the main activity of the AHKGA, whose logic model is presented in Figure 2. AHKGAs mission is to "power the global movement to get kids moving" by means of thought leadership, knowledge translation and mobilization, capacity building, and advocacy. This is facilitated by sustainable partnerships and cross-sectoral collaborations that enable best practice exchanges, networking, and cross-fertilization.

The development and the publication of the individual country Report Cards and Global Matrices aim to facilitate capacity building among the researchers and stakeholders involved, to decrease surveillance gaps and increase understanding of the state of childhood physical activity, and to create relevant networks and partnerships. A long-term goal of AHKGA activities is to contribute to the creation of relevant policy actions for the promotion of physical activity in various contexts to help attain the third 
Physical Inactivity: identified as the $4^{\text {sh }}$ leading risk factor of NCDs and responsible for $9 \%$ of premature mortality Increasing Global Prevalence of Physical Inactivity: $23 \%$ for aduits and $81 \%$ for adolescents aged 11 to 17 years (in 2016)

International Calls for Action

2010 - GAPA: Toronto Charter for Physical Activity

Global call for political/social commitment to support health.

enhancing physical activity for all.

3 concerted actions for successful population change:

- Implement a national policy and action plan

- Introduce policies that support physical activity

- Develop partnerships for action

2011 - UN: Meeting of the General Assembly for the Prevention and Control of NCDs

Declaration: Governments/international communities must act to address the common risk factors of NCDs including physical inactivity.

2013 - WHO: Re-edition of the Action Plan for the Global StrategY for the Prevention and Control of NCDs (2013-2020)

Six main objectives and 9 main targets including a global relative reduction of $10 \%$ in prevalence of insufficient physical activity

2015- UN: Transforming our world: The 2030 agenda for sustainable development

Objective: To end all forms of poverty, fight inequalities and tackle climate change via a specific set of goals.

The 17 Sustainable Development Goals [SDGs] are divided into 169 specific targets and aimed to be achieved over the next 15 years.

2016 - Bangkok Declaration on Physical Activity for Global Health and Sustainable Development

Position statement on the importance of physical activity for global health, the prevention of NCDs and how the co-benefits of population based actions on physical activity can contribute to achieving 8 of the 17 SDGs

\section{6 - WHO: Report of the Commission on Ending Childhood} Obesity

Set of recommendations including physical activity promotion to successfully tackle childhood and adolescent obesity in different contexts around the world.

\section{8 - WHO: Global Action Plan on Physical Activity 2018-2030}

Provide guidance to support the implementation of national multisectoral physical activity actions which leverage the links and benefits to sectors beyond health and to national economic and sustainable development.

4 strategic objectives: creating an active society, creating active environments, creating active lives, and creating active systems.

\section{Report Cards and Global Matrices}

2005-Creation of the Report Card on Physical Activity for Children and Youth (Canadian-focused)

- Public-facing document reporting letter grades, updated scientific information, research gaps and recommendations for improvement on physical activity indicators for children and youth

- Designed to serve as a knowledge translation tool and to increase and accelerate the dissemination of research

\section{5-2014 Report Card on Physical Activity for Children and Youth} expansion

- 10 Canadian Report Cards published (one per year)

- 5 national Report Cards developed in other countries

2014 - Global Matrix 1.0 on Physical Activity Grades for Children and Youth

- The Report Card process was replicated through a harmonized development process in 15 countries from $S$ continents, constituting the first edition of the Glabol Matrix

2014 - Formation of the Active Healthy Kids Global Alliance

- International network of researchers, health professionals and stakeholders, working together to power the movement to get kids moving around the world

- Identified strengths, disparities, inequities, research and surveillance gaps across countries

2016- Global Matrix 2.0 on Physical Activity Grades for Children and Youths

- Good representation of most areas of the world was achieved (38 national Report Cards)

- Provided a useful framework for consolidating and assessing the best available evidence aimed at understanding physical activity differences between and within countries

2018 - Incorporation of AHKGA as a not-for-profit organization

2018 - Global Matrix 3.0 on Physical Activity Grades for Children and Youths

- 49 countries from 6 continents

- Physical activity trends for each $\mathrm{HOl}$ grouping, as well as research and surveillance gaps

- Low engagement in physical activity and related behaviors were observed across countries, confirming the state of crisis of children and youth physical activity globally

Figure 1 - Integration of the Report Cards and global matrices of physical activity grades for children and youth in the context of global efforts and activities for the promotion of physical activity. Sources: Toronto Charter for Physical Activity, ${ }^{16}$ Report of the Secretary General for the Prevention and Control of Noncommunicable Diseases, ${ }^{17}$ Action Plan for the Global Strategy for the Prevention and Control of NCDs (2013-2020), ${ }^{18}$ Transforming Our World: the 2030 Agenda for Sustainable Development, ${ }^{19}$ Bangkok Declaration on Physical Activity for Global Health and Sustainable Development, ${ }^{20}$ Report of the Commission on Ending Childhood Obesity ${ }^{21}$ Global Action Plan on Physical Activity 2018-2030, ${ }^{22}$ Global Matrix 1.0 on Physical Activity for Children and Youth, ${ }^{11}$ Global Matrix 2.0 on Physical Activity for Children and Youth, ${ }^{16}$ and Global Matrix 3.0 on Physical Activity for Children and Youth. ${ }^{23}$ Note: AHKGA indicates Active Healthy Kids Global Alliance; GAPA, Global Advocacy for Physical Activity; HDI, Human Development Index; NCDs, noncommunicable diseases; UN, United Nations; WHO, World Health Organization. 
Table 1 Grading Scheme and Numerical Equivalents for Analysis for the Global Matrix 1.0 and Global Matrix 2.0

\begin{tabular}{llc}
\hline Grade & Interpretation & Numerical equivalents for analysis \\
\hline A & We are succeeding with a large majority of children and youth $(\geq 80 \%)$. & 5 \\
B & We are succeeding with well over half of children and youth $(60 \%-79 \%)$. & 4 \\
C & We are succeeding with about half of children and youth $(40 \%-59 \%)$. & 3 \\
D & We are succeeding with less than half but some children and youth $(20 \%-39 \%)$. & 2 \\
F & We are succeeding with very few children and youth $(<20 \%)$. & No grade \\
INC & Incomplete-inadequate information to assign a grade. & 1 \\
\hline
\end{tabular}

Vision

\begin{tabular}{|c|c|c|c|c|}
\hline Activities & \multicolumn{3}{|c|}{$\begin{array}{l}\text { Lead the development of the } \\
\text { Global Matrices and the country } \\
\text { Report Cards }\end{array}$} & Global Fitne \\
\hline Resources & \multicolumn{2}{|c|}{$\begin{array}{c}\text { Expertise and leadership of } \\
\text { members of AHKGA }\end{array}$} & \multicolumn{2}{|c|}{$\begin{array}{l}\text { Funding or econom } \\
\text { resources derived frc } \\
\text { membership fees }\end{array}$} \\
\hline Outputs & \multicolumn{4}{|c|}{$\begin{array}{l}\text { Global Matrices; country Report Cards; Media and } \\
\text { Organization and participation in congresses and c } \\
\text { Knowledge exchange with governments and non-g }\end{array}$} \\
\hline $\begin{array}{l}\text { Immediate } \\
\text { Outcomes }\end{array}$ & $\begin{array}{l}\text { Capacity } \\
\text { building: } \\
\text { Trained and } \\
\text { mentored } \\
\text { researchers } \\
\text { and staff for } \\
\text { the surveillance } \\
\text { of physical } \\
\text { activity grades } \\
\text { for children } \\
\text { and youth }\end{array}$ & $\begin{array}{l}\text { Decreased } \\
\text { physical ac } \\
\text { surveillane } \\
\text { and increa } \\
\text { understan } \\
\text { children a } \\
\text { youth phy } \\
\text { activity co } \\
\text { among kno } \\
\text { users arou } \\
\text { world }\end{array}$ & & $\begin{array}{l}\text { Creation of } \\
\text { national and } \\
\text { international } \\
\text { networks of } \\
\text { physical } \\
\text { activity } \\
\text { leaders at } \\
\text { each } \\
\text { country } \\
\text { level }\end{array}$ \\
\hline
\end{tabular}

Government and non-government stakeholders create policies, programs and campaigns that increase physical activity opportunities for children and youth, and parents create cpportunities

Outcomes

\section{"A world of Active Healthy Kids"}

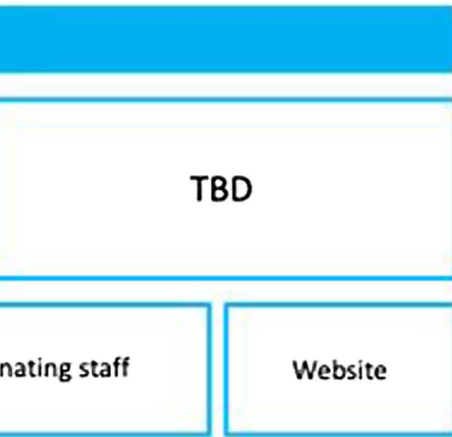

Intermediate

\begin{tabular}{l||l|}
\hline $\begin{array}{l}\text { Partnerships created } \\
\text { with relevant } \\
\text { organizations to } \\
\text { advance knowledge } \\
\text { and advocate for } \\
\text { changes to policies } \\
\text { and programs that } \\
\text { increase physical } \\
\text { activity } \\
\text { opportunities for } \\
\text { children and youth }\end{array}$ & $\begin{array}{l}\text { Increased } \\
\text { awareness } \\
\text { among decision- } \\
\text { makers and in } \\
\text { the media about } \\
\text { the importance } \\
\text { of physical } \\
\text { activity for the } \\
\text { health of } \\
\text { children and } \\
\text { youth }\end{array}$ \\
\hline
\end{tabular}

Increased

recognition of AHKGA as a reliable source of data about physical activity of children and youth, and as an advocate for physical activity promotion

Long term outcome

All children and youth in the world are physically active enough to benefit their health

Figure 2 - AHKGA logic model. Note: AHKGA indicates Active Healthy Kids Global Alliance; TBD, to be determined.

global target of the Action Plan for the Global Strategy for the Prevention and Control of Noncommunicable Diseases: "a 10\% relative reduction in prevalence of insufficient physical activity." 18

The number and distribution of national Report Cards that have been produced and released as the first Canadian-focused document are presented in Figure 3, and the year, country, and web link (when available) to each of these Report Cards are presented in Supplementary Material 1 (available online). In total, 122 national Report Cards, distributed among 53 different countries, have been developed and published. A total of 13 Canadian Report Cards have been published, while the number of Report Cards for the other participating countries is between 1 and 3, with the exception of South Africa $(n=5)$ and Mexico $(n=4)$. There are also several other jurisdictions (eg, cities, provinces, and states) that have replicated the Report Card between 2008 and 2012 (not presented in Supplementary Material 1 [available online]). These Report Cards have already been reported in the previous impact article. ${ }^{13}$

The development of 122 country-level Report Cards distributed across the world highlights the international collaborations between teams of researchers and stakeholders assigning grades to multiple physical activity indicators. To gain insights on the number of people collaborating on the Global Matrix 3.0, Report Card leaders from 49 countries were asked to report the name, title, and city of residence for each member of their Report Card working group. The latitude and longitude coordinates for the center of each city were determined using www.latlong.net, and an identification number was assigned to each individual report. These data were used to build and visualize the network of researchers and staff 
A

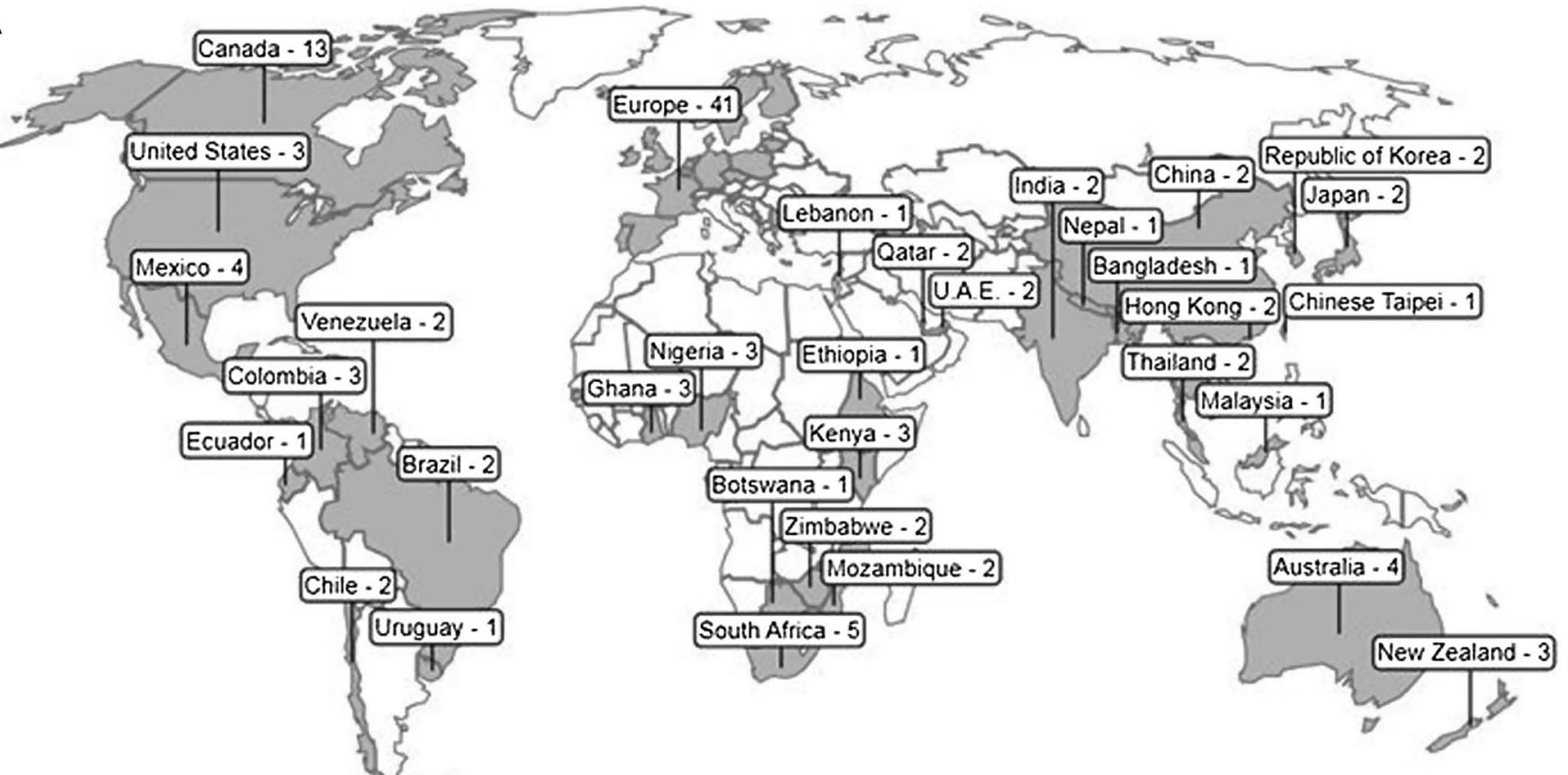

B

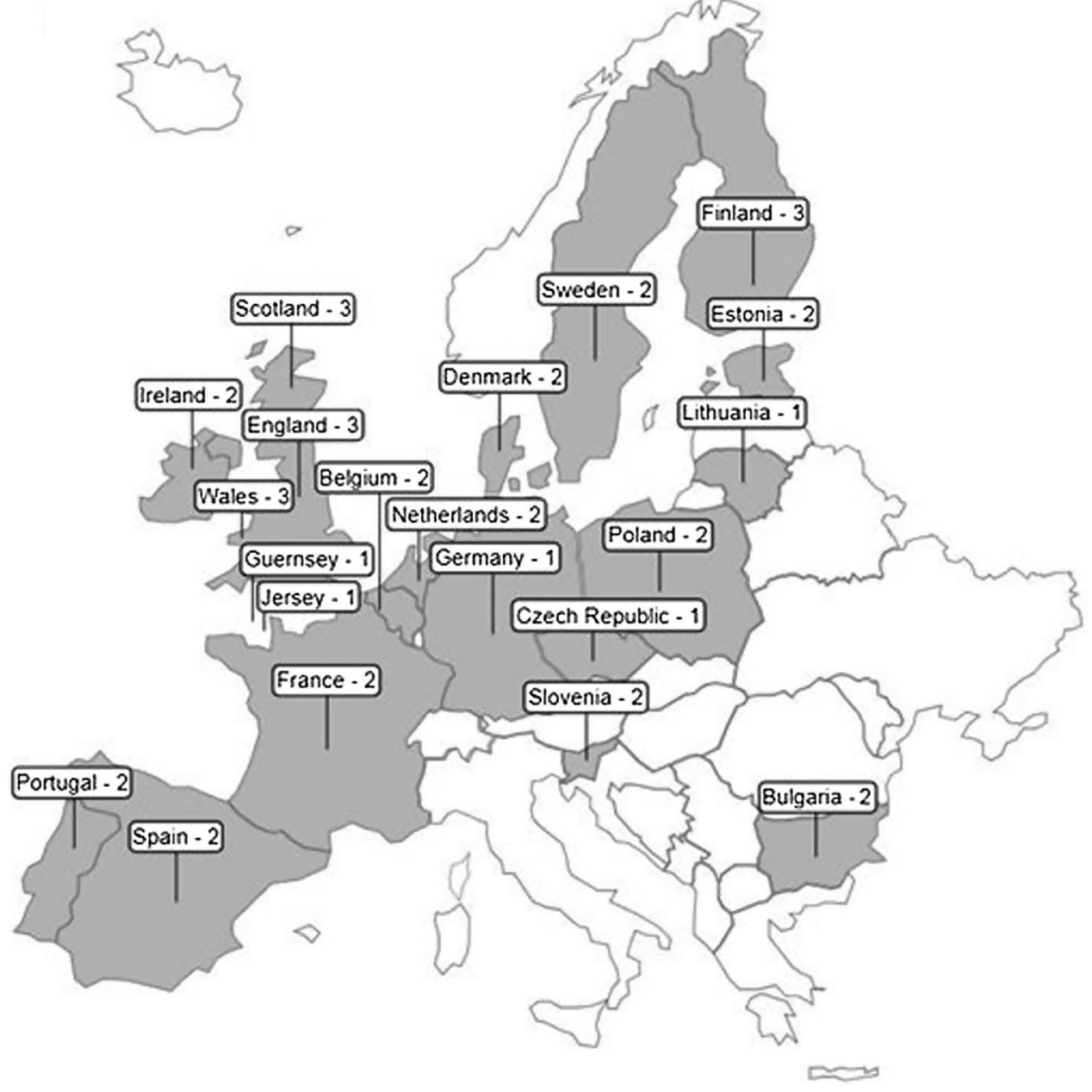

Figure 3 - Distribution of national Physical Activity Report Cards for Children and Youth developed and released between 2005 and 2019. (A) In the world. (B) Zoom on European countries. 
involved in the AHKGA Global Matrix 3.0. The network was visualized with Gephi tool (gephi.org; Gephi Consortium, Compiègne, France), and the GeoLayout plugin was used to add the geographical attributes of the members of the network. In total, 513 individuals ( 257 men and 256 women) were reported as Report Card working group members. Figure 4 presents the AHKGA Global Matrix 3.0 network. In this network, blue links were generated to illustrate the collaborations between the AHKGA members-within each country's Report Card working group members and between the Report Card leaders/co-leaders, their respective intermediate mentors, continent leaders, and the AHKGA coordinating headquarters (Ottawa, Canada). Although there is a good representation of people in Europe, North and South America, there is still a lack of representation in AHKGA membership from North Africa, North and Southeast Asia, and the South Pacific Islands. Figure 4 shows that even if most of the countries in the world are still not part of this international initiative, the Global Matrix 3.0 brought researchers and stakeholders from most geographical regions together, collaborating to advocate for the promotion of physical activity among children and youth.

\section{Changes in Report Card Grades Nationally and Internationally}

Grades from the Global Matrix 1.0 and Global Matrix 2.0 were used to calculate the average grade for each Report Card indicator. The letter grades were converted to a numerical value, following a standard scale format for Global Matrix 1.0 and Global Matrix 2.0 (see Table 1), and using an updated scale for Global Matrix 3.0 (see Table 2). A numerical average was calculated and then converted back to the corresponding letter grade. Incomplete (INC) grades were assigned when the information available was insufficient or inadequate to assign a grade and were not included in the calculation of the average grade. If the numerical average resulted in a decimal, the floor value was converted back to a letter.

Table 3 shows the average grades per indicator and the number and percentage of INC grades per indicator for Global Matrix 1.0, Global Matrix 2.0, and Global Matrix 3.0. The average grades per indicator were stable between the Global Matrix 1.0 and Global Matrix 2.0, despite the participation of 23 additional countries. The only difference observed was a decrease from " $C$ " to " $D$ " for the Active Play indicator. Similarly, the average grades per indicator also remained the same between Global Matrix 2.0 and Global Matrix 3.0, despite modifications to the benchmarks and grading scale, and despite the addition of 11 new countries to the Global Matrix 3.0. Exceptions were observed for Active Play (increased from "D" to "D+"), Sedentary Behaviors (increased from "D" to "D+"), and Family and Peers (decreased from "C" to "D+"). Overall, an average grade of "C," "C," and " $\mathrm{C}$-" was observed for the Global Matrix 1.0, Global Matrix 2.0, and Global Matrix 3.0, respectively. This relative stability may represent a "mass average effect" as changes to the grades were more apparent at the country level.

An increase of INC grades was observed for each indicator between the Global Matrix 1.0 and the Global Matrix 2.0. Similarly, the number of INC grades increased for each indicator between Global Matrix 2.0 and Global Matrix 3.0, except for Organized Sport Participation, Active Transportation, and

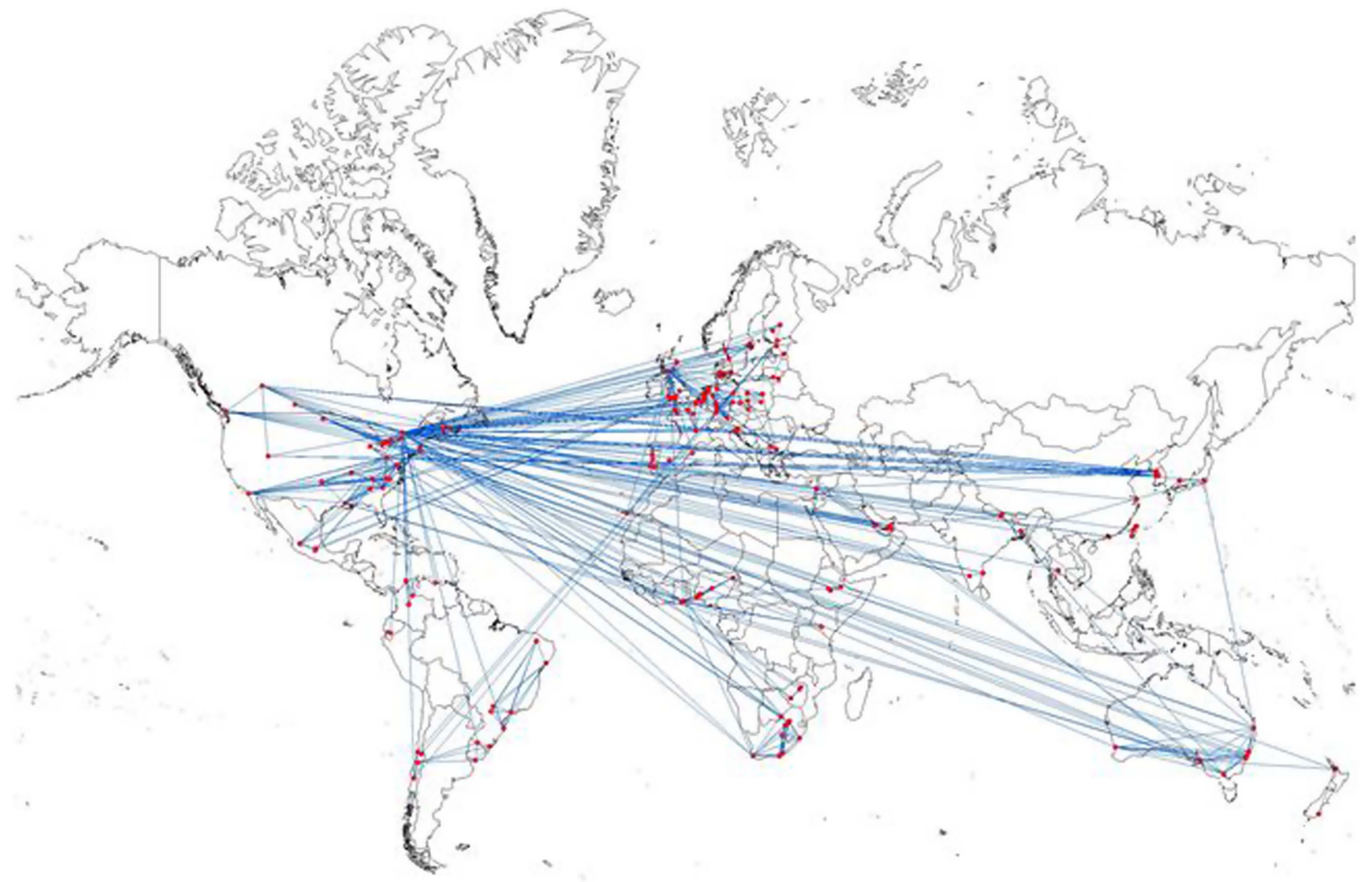

Figure 4 - Distribution of the 513 members of Report Card work groups across the world and illustration of the AHKGA network. Note: Only one node appears per city even if there is more than one AHKGA member from the city. AHKGA indicates Active Healthy Kids Global Alliance. 
Table 2 Grading Scheme and Numerical Equivalents for Analysis for the Global Matrix 3.0

\begin{tabular}{|c|c|c|}
\hline Grade & Interpretation & $\begin{array}{c}\text { Numerical equivalents } \\
\text { for analysis }\end{array}$ \\
\hline $\mathrm{A}+$ & $94 \%-100 \%$ & 15 \\
\hline A & We are succeeding with a large majority of children and youth $(87 \%-93 \%)$ & 14 \\
\hline A- & $80 \%-86 \%$ & 13 \\
\hline $\mathrm{B}+$ & $74 \%-79 \%$ & 12 \\
\hline B & We are succeeding with well over half of children and youth $(67 \%-73 \%)$ & 11 \\
\hline B- & $60 \%-66 \%$ & 10 \\
\hline $\mathrm{C}+$ & $54 \%-59 \%$ & 9 \\
\hline $\mathrm{C}$ & We are succeeding with about half of children and youth $(47 \%-53 \%)$ & 8 \\
\hline $\mathrm{C}-$ & $40 \%-46 \%$ & 7 \\
\hline $\mathrm{D}+$ & $34 \%-39 \%$ & 6 \\
\hline $\mathrm{D}$ & We are succeeding with less than half but some children and youth $(27 \%-33 \%)$ & 5 \\
\hline D- & $20 \%-26 \%$ & 4 \\
\hline $\mathrm{F}$ & We are succeeding with very few children and youth $(<20 \%)$ & 2 \\
\hline INC & Incomplete-insufficient or inadequate information to assign a grade & No grade \\
\hline
\end{tabular}

Table 3 Comparison of Average Grades and Incomplete Grades Per Indicator Between Global Matrix 1.0 (15 Participating Countries), Global Matrix 2.0 (38 Participating Countries), and Global Matrix 3.0 (49 Participating Countries)

\begin{tabular}{|c|c|c|c|c|c|c|}
\hline \multirow[b]{2}{*}{ Indicator } & \multicolumn{3}{|c|}{ Average grade } & \multicolumn{3}{|c|}{$\begin{array}{c}\text { Number and percentage of countries } \\
\text { with incomplete grade }\end{array}$} \\
\hline & $\begin{array}{c}\text { Global } \\
\text { Matrix } 1.0\end{array}$ & $\begin{array}{c}\text { Global } \\
\text { Matrix } 2.0\end{array}$ & $\begin{array}{c}\text { Global } \\
\text { Matrix 3. } 0\end{array}$ & $\begin{array}{c}\text { Global } \\
\text { Matrix } 1.0\end{array}$ & $\begin{array}{c}\text { Global } \\
\text { Matrix } 2.0\end{array}$ & $\begin{array}{c}\text { Global } \\
\text { Matrix } 3.0\end{array}$ \\
\hline Overall Physical Activity & $\mathrm{D}$ & $\mathrm{D}$ & $\mathrm{D}$ & $0(0 \%)$ & $1(3 \%)$ & $2(4 \%)$ \\
\hline Organized Sport Participation & $\mathrm{C}$ & $\mathrm{C}$ & $\mathrm{C}$ & $2(13 \%)$ & $7(18 \%)$ & $7(14 \%)$ \\
\hline Active Play & $\mathrm{C}$ & $\mathrm{D}$ & $\mathrm{D}+$ & $10(67 \%)$ & $21(55 \%)$ & $29(59 \%)$ \\
\hline Active Transportation & $\mathrm{C}$ & $\mathrm{C}$ & $\mathrm{C}$ & $1(7 \%)$ & $3(8 \%)$ & $2(4 \%)$ \\
\hline Sedentary Behaviors & $\mathrm{D}$ & $\mathrm{D}$ & $\mathrm{D}+$ & $2(13 \%)$ & $3(8 \%)$ & $3(6 \%)$ \\
\hline Physical Fitness & N/A & N/A & $\mathrm{C}-$ & N/A & N/A & $27(55 \%)$ \\
\hline Family and Peers & $\mathrm{C}$ & $\mathrm{C}$ & $\mathrm{D}+$ & $9(60 \%)$ & $17(45 \%)$ & $22(45 \%)$ \\
\hline School & $\mathrm{C}$ & $\mathrm{C}$ & $\mathrm{C}$ & $1(7 \%)$ & $4(10 \%)$ & $8(16 \%)$ \\
\hline Community and Built Environment & $\mathrm{C}$ & $\mathrm{C}$ & $\mathrm{C}$ & $3(20 \%)$ & $11(29 \%)$ & $13(27 \%)$ \\
\hline Government Strategies and Investment & $\mathrm{C}$ & $\mathrm{C}$ & $\mathrm{C}$ & $5(33 \%)$ & $6(16 \%)$ & $8(16 \%)$ \\
\hline Average & $\mathrm{C}$ & $\mathrm{C}$ & $\mathrm{C}-$ & $3.7(24 \%)$ & $8.1(21 \%)$ & $12.2(25 \%)$ \\
\hline
\end{tabular}

Sedentary Behaviors. However, given the difference in the number of countries involved in the 3 Global Matrices, comparing the proportion of INC indicators rather than the absolute value is more relevant. Overall, the proportion of INC grades per Global Matrix was stable over time (see Table 3).

To compare the evolution of the grades by country, the comparison of average grades and INC grades over time per country that participated in Global Matrix 1.0 (2014), Global Matrix 2.0 (2016), and Global Matrix 3.0 (2018) is presented in Table 4. Overall, Table 4 shows that the average grades were stable over time between Global Matrix 1.0 and Global Matrix 2.0. Given the spread of possible values within a letter grade, 2 years is likely not a long enough period to observe a significant letter grade change among the physical activity indicators, particularly with regard to Overall Physical Activity and Sedentary Behaviors. The stability of the grades between the Global Matrix editions may be an indicator of reliability of the Report Cards' standardized development process. In addition, half of the participating countries reported fewer INC grades in subsequent Report Cards, and this decreased number of INC grades suggests improvements in the surveillance of physical activity indicators in these countries, which could potentially be a positive effect of their participation in the Global Matrix initiative.

\section{Case Study: Changes in Report Card Grades Over Time in Canada, South Africa, and Mexico}

As a result of several countries producing Report Cards before the Global Matrix 1.0 in 2014, more meaningful comparisons of their grade changes over time were able to be made. Report Cards in Canada were developed and published every year from 2005 to 2016 and biannually after 2016. Changes in grades between 2005 and 2016 were analyzed by Barnes and Tremblay. ${ }^{14}$ A total of 25 grade changes were observed over time. Specifically, 64\% 


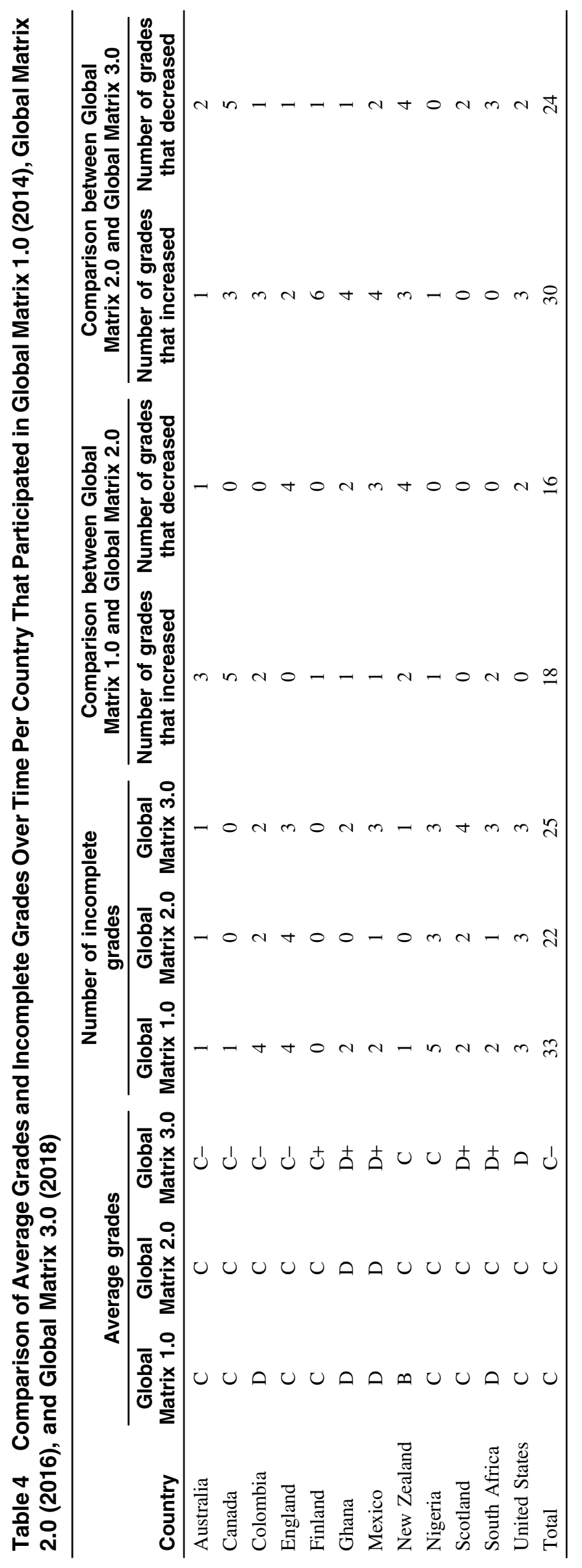


$(16 / 25)$ of the grade changes was observed, and $70 \%(7 / 10)$ of child and youth physical activity indicator changes in Canada was improved over time. The majority of the observed grade changes $(68 \% ; 17 / 25)$, however, were in relation to 5 indicators: Family and Peers, School, Community and Built Environment, Government Strategies and Investment, and Nongovernment (an additional indicator in the Canadian Report Card). These changes represented structural and environmental improvements in contrast to individual behavioral improvements (eg, improved grades in Active Transportation and Sedentary Behaviors), which have undergone very little progress over time.

In South Africa, 5 Report Cards have been developed between 2007 and 2018, but the physical activity indicators used for these Report Cards have changed over time, limiting their across-year comparison. However, physical activity was consistently evaluated, and small changes were observed over time ("C-" in 2007, "D" in 2010, "D" in 2014, "C" in 2016, and "C" in 2018). This indicates that about half of the children and youth in South Africa are meeting the recommended 60 minutes of moderate- to vigorousintensity physical activity daily. ${ }^{28} \mathrm{~A}$ finding consistently observed in the 5 South African Report Cards was the absence of nationally representative data, limiting the validity and reliability of their physical activity grades, which were based on local and regional studies. ${ }^{28-30}$

Finally, 4 Report Cards have been developed in Mexico between 2012 and 2018. Some negative trends concerning the Overall Physical Activity ("C" in 2012, "C+" in 2014, "C" in 2016, and "D+" in 2018) and Sedentary Behaviors grades ("C" in 2012, "D" in 2014, "D" in 2016, and "D-" in 2018) were observed across 6 years. In contrast, a positive trend was observed for the Community and Environment grades (INC in 2012, "F" in 2014, "D" in 2016, and "D+" in 2018) across the 6-year period. An encouraging finding from the comparison of Mexico's Report Cards is the increasing number of indicators that the working group was able to assign grades (4 in 2012 and 7 in 2018), indicating an increase in availability of physical activity data within the country. ${ }^{31-33}$

More details concerning the country physical activity grades are available in the Report Card documents listed in Supplementary Material 1 (available online) and in the articles listed in Supplementary Material 2 (available online).

\section{Impact on Raising Awareness and Capacity Building in the National and International Scientific Community}

\section{Scientific Publications Related to the Report Cards and the Global Matrices}

Since its creation, the Report Card has received much attention in the research community, nationally and internationally. Report Cards and related articles published since 2005 are summarized in Supplementary Material 2 (available online), including the scientific articles associated with specific Report Cards (where available), in addition to the international comparison articles and additional secondary analyses using data from the Report Cards or Global Matrices.

A first draft of this list of articles was created with a database search conducted using PubMed on March 26, 2019, with filters capturing articles published in 2015 or later. The search terms used were "report card on physical activity" and "report card global matrix"; 51 relevant peer-reviewed articles were captured. The list was then completed by the members of the AHKGA executive committee. The articles included in the final version of the list were then entered into the Scopus database to determine the number of times each article had been cited and into the Google Scholar database to confirm and cross-reference the number of times each article had been cited in the literature. Duplicate citations and citations from non-peer-reviewed articles were excluded from the count. The 49 short Report Card articles that were published in 2018 in the supplemental issue of the Journal of Physical Activity and Health were treated as peer-reviewed articles for this analysis. Although these articles were externally audited before publication, they did not go through a formal peer-review process.

In total, the Global Matrix and Report Card initiatives have generated many impactful publications: 149 scholarly articles have been published, accumulating more than 1600 citations at the time of the count. The Journal of Physical Activity and Health was the host of 3 Global Matrix Special Supplements and was therefore the most reported journal in this list $(n=118)$; however, 31 peer-reviewed publications in 13 other journals were also reported.

\section{Scientific Oral Presentations and Posters Related to the Report Cards and the Global Matrices}

In addition to the publication of many articles, a great number of oral and poster presentations including symposia related to the Report Cards or the Global Matrix were made at international scientific conferences, meetings or congresses, as well as at national and local events. A poster was presented for each country Report Card at the release of the Global Matrix 1.0 at the Global Summit on the Physical Activity of Children in Toronto, Canada, in 2014; at the release of the Global Matrix 2.0 at the International Society of Physical Activity and Health Congress in Bangkok, Thailand, in 2016; and at the release of the Global Matrix 3.0 at the Movement to Move Event in Adelaide, Australia, in 2018. In addition, numerous other posters, oral presentations, and symposiums have been delivered. A list of the academic presentations including those related to the Report Cards or the Global Matrices that were reported by AHKGA members is presented in Supplementary Material 3 (available online).

In total, 240 academic presentations, including 7 keynote presentations, 9 invited presentations, 81 oral presentations, 22 oral presentations from symposia, 1 panel discussion, and 120 poster presentations were performed at 84 different international, national, or local events.

\section{Impact on Research Gap Surveillance}

For each participating country, research and surveillance needs were highlighted using 2 mechanisms as follows: (1) the INC grades in the Report Card documents and Report Card articles and (2) the research gap section included in several articles related to the Report Cards. An INC grade is a formal way to communicate a call for action to the health surveillance community, concerned researchers, and interested end users. Similarly, the identified research gaps published in peer-reviewed articles highlight relevant research and publication opportunities for researchers.

The decrease in INC grades associated with the availability of new physical activity data in a given country cannot be automatically considered to be a positive effect of the Report Card or Global Matrix process. However, several cases of new physical activity surveillance projects directly resulting from the participation of a 
country in the Global Matrix were reported to the AHKGA. For example, in Thailand, the Report Card working group developed the Thailand Physical Activity Children Survey 2015, a nationally representative school-based survey used to collect data for each Report Card physical activity indicator for their participation in the Global Matrix 2.0 in 2016. ${ }^{34}$ On a smaller scale, Report Card leaders from Canada and Ethiopia reported planning to survey key government officials to identify the past and present policies and actions in place for promoting physical activity among children and youth.

Numerous Report Card team members also reported initiating some work to cover the gaps highlighted by their first or previous Report Card(s) and were able to collect new data before starting the development of their next Report Card. For example, China's first Report Card (in 2016) focused only on data collected in Shanghai, highlighting the need for nationally representative data. The Chinese Report Card working group managed to obtain support for and developed the "Physical Activity and Fitness in China - The Youth Study" (PAFCTYS) in 2016. The PAFCTYS is a national surveillance protocol that covers the evaluation of the 10 common physical activity indicators of the Global Matrix from a nationally representative group of school children across the country and is now conducted on a yearly basis. ${ }^{35}$ Similarly, in Colombia, the first and second versions of the national Report Card identified research gaps in the national surveillance of physical activity. This helped to advocate for the inclusion of a broader age group (3-17 y) and new components to assess physical activity among children and youth in the latest version of the National Survey of Nutrition (2015), ${ }^{36}$ which is the main source of data on physical activity at the national level in Colombia. Another example was observed in Scotland, where following the release of the Global Matrix 2.0 in 2016, the Report Card team managed to obtain an agreement from the Scottish Health Survey (the main annual health surveillance mechanism in Scotland), which agreed to modify the reporting of specific health data. Scottish Health Surveys were revised in 2018 to distinguish between compliance with recommendations for early years and school-age children and to improve the way active and outdoor play is reported. The reporting of these indicators will also be changed so that data from school-age children can be extracted separately from adult data and graded in future Scottish Report Cards. Finally, the leader of V4SPORT Foundation, the organization that led the Report Card for Poland, reported that their participation in Global Matrix 2.0 helped the organization to acquire funds to measure physical fitness of over 10,000 kids in Poland.

\section{Impact on Capacity Building Among Physical Activity Researchers Around the World}

The Report Card and the Global Matrix development is a long process involving a structured and harmonized approach as well as collective mentorship by experienced AHKGA members. In addition to the generation of new scientific knowledge and authorship/publications and presentations, participation in the Global Matrix initiative has had beneficial impacts for teams of researchers from around the world by providing the opportunity for the development of new skills in project management, data synthesis, advocacy, knowledge translation, and national and international collaboration.

In fact, after the development of their national Report Cards in 2018, 19 (38\%) Report Card leaders declared that this process allowed them to uncover physical activity data they were not aware of, and 33 (67\%) Report Card leaders reported that they expected their Report Card to improve their ability to keep up with research in the field, identify research gaps, and address surveillance needs. Several Report Card leaders articulated how their participation in the Global Matrix was a valuable learning and training experience with the help of the AHKGA board members. The Botswana Report Card leader stated that "this has been a great opportunity for the Botswana team as we learnt a lot from working with you all. It has opened up an area of very important research that has been lacking"; similarly, the Report Card leader of Bulgaria commented that "since I'm not a researcher myself and don't have the background, it was a bit more difficult to create the two-page Report Card. I managed, thanks to the support of the AHKGA team and mentors. [. . .] The lack of academic background was a challenge for the participation and the contribution to the HDI grouping article, but it was also an opportunity to be part of the process and to understand it better."

Furthermore, 8 (16\%) Report Card leaders reported that they believed that their Report Card created program development and training, and one commented that the development of the Report Card was a training opportunity for "young researchers."

The AHKGA represents a great network of researchers, health professionals, and stakeholders who are working together for the promotion of healthy active lifestyles among children and youth, as presented in Figure 4. The development of the Report Cards and the Global Matrices creates networking opportunities for all participants involved. Early career researchers have the opportunity to work closely with high-profile researchers in the field of physical activity and health, creating several partnerships between researchers and between researchers and relevant organizations within their country. Several Report Card leaders declared that they expected their Report Card to "power the movement to get kids moving" by forming partnerships ( $\mathrm{n}=23$ or $47 \%)$ and by improving communications and public relations $(\mathrm{n}=26$ or $53 \%)$. In addition, according to the leader of Lebanon's Report Card, the Report Cards contributed to "building bridges across cultures and communities," and the leader of South Africa's Report Card stated that "it is a good exercise to bring together experts in the field and consolidate the available evidence." The leader of the United States' Report Card also commented that the Global Matrix provides a "strengthening of networks for research and practice at the regional level, as well as the identification of opportunities to work together with other countries to solve similar difficulties in the promotion of physical activity among children." The leader of Botswana's Report Card even reported that their participation in the Global Matrix 3.0 allowed them to "now have a research team to also work on other projects." Finally, in accordance with these findings, 47 Report Card leaders (96\%) reported that participating in the Global Matrix 3.0 was professionally rewarding.

\section{Impact on Generating Funds for Participating Countries and Individuals}

The funding of the Global Matrix project has evolved over time. The Global Matrix 1.0 was orchestrated by Active Healthy Kids Canada that funded it through internal sources and revenues from the 2014 Global Summit. The publication cost for the 2014 Report Card and Global Matrix 1.0 articles as open access in the Journal of Physical Activity and Health was similarly covered by Active Healthy Kids Canada. Nine travel scholarships were awarded to leaders of Report Cards from low- and middle-income countries through a grant from the International Development Research Centre (www.idrc.ca). Countries receiving subsidies included Ghana $(n=1)$, South Africa $(n=3)$, Colombia $(n=1)$, Malaysia $(\mathrm{n}=2)$, Kenya $(\mathrm{n}=1)$, and Mexico $(\mathrm{n}=1)$. 
In contrast to its previous edition, the Global Matrix 2.0 was funded by the participating countries. All countries that registered for the Global Matrix 2.0 had to pay a registration fee of US \$500. The money was used for project management, development of the AHKGA website, publication costs of all the country Report Card articles and the Global Matrix 2.0 comparison article in a special supplement in the Journal of Physical Activity and Health, and participating country gifts.

As the funds from the Global Matrix 2.0 were marginally sufficient to cover the associated costs, the registration fees were modified for the Global Matrix 3.0. Instead of a flat fee, the AHKGA Executive Committee decided to adopt a fee structure based on current Human Development Index (HDI) rankings by country as follows:

(1) Low HDI countries: US $\$ 500$

(2) Medium HDI countries: US $\$ 750$

(3) High HDI countries: US $\$ 1000$

(4) Very High HDI countries: US $\$ 1500$

In exceptional circumstances, special rates were approved for some countries. This money was used to finance the creation of a new AHKGA website, the publication of the 49 Report Card scholarly articles in 2018 and the 4 integrated articles in a special supplement of the Journal of Physical Activity and Health, the creation of gifts and awards for the Report Card leaders, a strategic planning meeting of the AHKGA Board members in early 2018, and the technical and research support and coordination of the Global Matrix 3.0.

In addition, during the early stages of the development of the Global Matrix 3.0, a fundraising committee was created within the AHKGA Board. The aim of the AHKGA fundraising committee is to brainstorm strategies to attract new sources of funding through sponsorships, partnerships, and parallel activities to reduce or ideally eliminate the Global Matrix registration fees for the participating countries, support specific research/surveillance projects, and potentially offer scholarships/grants to Report Card working groups in the future. No new sources of financial support have been secured yet, but the AHKGA Board members will focus on this before the commencement of the Global Matrix 4.0.

Finally, for each iteration of the Global Matrix, the AHKGA encouraged all Report Card working groups to apply for funding to financially support the development, design, and printing of their Report Card, and to allow a representative to travel to the international Global Matrix release event. In 2017, during the early stage of Global Matrix development, a document summarizing a review of the international calls for surveillance and promotion of physical activity was provided by AHKGA to all the Report Card working groups involved to support their potential grant applications. In 2016, Report Card leaders from 22 out of 38 countries reported that they had internal or external funding to develop and produce their Report Card, and 23 reported that they had internal or external funding at least partially covering their travel and attendance at the release of the Global Matrix 2.0 at the 6th Congress of the International Society of Physical Activity and Health in Bangkok, Thailand. In 2018, Report Card leaders from 30 out of 49 countries declared that they applied for funding or sponsorship to support the production of their Report Card, and/or their travel to the Global Matrix 3.0 release at the Movement to Move Event in Adelaide, Australia. However, Report Card leaders from 23 countries reported that they secured funding only for the development of their Report Card, and Report Card leaders from 20 countries reported that they only had funding to partially or entirely cover their travel costs to the release of Global Matrix 3.0.

\section{Impact on Disseminating Information to the General Population and Stakeholders}

The Report Cards and the Global Matrices were created to "power the movement to get children and youth moving" nationally and internationally, through raising awareness about the importance of physical activity in terms of the health of children and youth among the general population, stakeholders, and decision makers. Indeed, parental support for physical activity is associated with children's physical activity, ${ }^{37,38}$ and as such, parents are one of the strategic targets of the Report Cards dissemination through the general media. Additional specific targets in these projects are concerned stakeholders and their related decision makers who have a vested interest in children's physical activity and health. The knowledge exchange between members from governmental and nongovernmental organizations can lead to the creation of policies, programs, and campaigns by government and nongovernment stakeholders, which, in turn, can help increase physical activity opportunities for children and youth. ${ }^{12}$

\section{Findings From Global Matrix 1.0}

Nearly 900 delegates from 31 countries were present at the Global Summit of Physical Activity for Children and Youth, and 288 delegates completed a survey after the event. Among the respondents, $10 \%$ reported to be from government agencies, $14 \%$ from a nongovernmental organization, and $15 \%$ from a public health organization. Based on the attendance breakdown, this event served as an ideal opportunity to raise awareness internationally among attending stakeholders. The media attention that was generated by the launch of the Global Matrix 1.0 was collected by Canada's Report Card working group. A total of 515 media hits (individual news stories), including 160 online, 57 print, 92 on television, and 206 on the radio were generated, achieving a total of 219 million media impressions nationwide within Canada.

\section{Findings From Global Matrix 2.0}

The release of the Global Matrix 2.0 took place during the Sixth International Congress on Physical Activity and Public Health in Bangkok, Thailand, in November 2016, where over 1000 international delegates were attending the conference. The number of media hits online, on television, in newspapers (printed), and on the radio generated by the launch of the Global Matrix 2.0 was reported by the Report Card leaders to the AHKGA. The total number of media hits per participating country is summarized in Figure 5A. This figure includes the reported media hits that were generated by the launch of the Global Matrix 2.0 and by the release of the country Report Cards. With the exception of Australia, Hong Kong, Thailand, and Canada, the reported impact on the mainstream media was small or nonexistent for most countries, with only 18 out of 38 countries reporting media hits. Most of the media hits generated in Hong Kong and Thailand were online, with 30 and 71 hits, respectively, whereas in Canada and Australia, most of the media hits generated were on the radio (213 hits for Canada and 59 for Australia) followed by online (116 in Canada and 10 in Australia). In the Global Matrix 2.0 post-launch survey circulated by the AHKGA to the 38 Report Card leaders, $72 \%$ reported that 

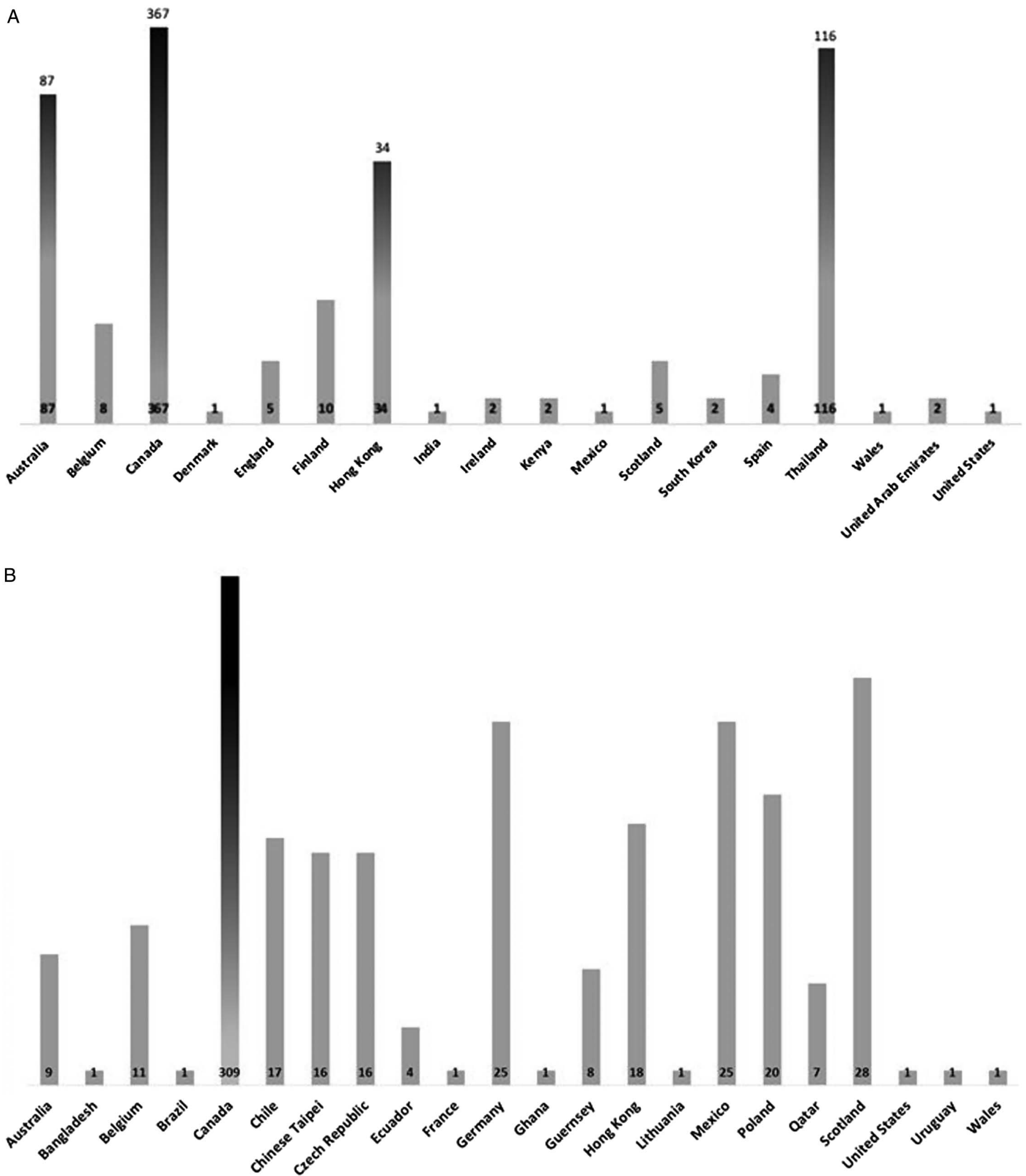

Figure 5 - Summary of the media attention reported by the Report Card leaders to AHKGA. (A) Media hits generated by the launch of the Global Matrix 2.0 (2016) and the publication of its related Report Cards. (B) Media hits generated by the launch of the Global Matrix 3.0 (2018) and the publication of its related Report Cards. Note: The size of the bars filled with a gradient was reduced for a better visualization of the graphics. AHKGA indicates Active Healthy Kids Global Alliance. 
they were satisfied with the media coverage for their Report Card, and $80 \%$ reported that they were satisfied with the overall media coverage for the Global Matrix 2.0 launch.

To support the dissemination of the Report Card and Global Matrix information in the media, several resources and specific instructions were provided by the AHKGA to the Report Card working groups before the release of the Global Matrix 2.0 and the release of the Global Matrix 3.0. These resources are detailed in the following section.

\section{Findings From Global Matrix 3.0}

The Global Matrix 3.0 was released on November 27, 2018 at the Movement to Move Event in Adelaide, Australia. A total of 161 delegates and speakers attended the event, including 97 attendees from Australia and 64 from 29 other countries. In anticipation of the launch of the Global Matrix 3.0 and of the country Report Cards, a detailed dissemination package was provided by the AHKGA to the Report Card working groups to support the dissemination of this information through various media outlets. This package included:

(1) Two infographics summarizing what the Global Matrix 3.0 is and its main findings.

(2) Social media material suggesting the use of specific hashtags and providing examples of Tweets/Facebook posts.

(3) Three press release documents: one focusing on the Global Matrix 3.0 and its findings, a neutral template that was adaptable to each country, and one focusing on findings at the country level (using Canada as an example).

(4) A sample article that could be used to promote the release of the Global Matrix 3.0 via websites or newsletters.

(5) A questions and answers document to provide guidance to the Report Card leaders when being interviewed by media.

All the Report Card leaders and communication coordinators in each country were encouraged by the AHKGA to use this material and to share, disseminate, and promote the launch of the Global Matrix 3.0 and their Report Card. The total number of media hits per participating country generated by the launch of the Global Matrix 3.0 and by the release of the national Report Card is summarized in Figure 5B, where only the countries with at least one media hit reported appear. A total of 521 media hits were reported by the Report Card leaders, including 309 hits for Canada alone. Twenty-two countries reported having one or more media hits, and 27 countries reported no media hits. In the Global Matrix 3.0 post-launch survey completed by the Report Card leaders, only $51 \%$ declared they were satisfied with the media coverage for their country Report Card. However, more than 3 quarters of respondents declared being satisfied with the overall media coverage for the Global Matrix 3.0.

Several possibilities may explain the large discrepancies with regard to media impact observed between the countries. Some countries did not officially release a Report Card document in addition to the launch of the Global Matrix. Countries also invested various amounts of time and effort to communicate with local and national media outlets, collect and synthesize media hits achieved, and report to the AHKGA. The timing of the releases may also have impacted media interest within each country as the space in media outlets is substantially higher when there is less news competition. Finally, it is possible that physical activity is not a priority in some countries, which may have contributed to the lack of media attention.
In Canada, great efforts were made to increase the dissemination and uptake of the Report Cards and Global Matrix findings to the media. Specific public relations and media strategies were established by Canada's Report Card working group to facilitate this exceptional impact. For every release of Canadian Report Card or Global Matrix, physical activity experts collaborated with communication professionals from ParticipACTION, the Canadian Report Card strategic communication partner, to develop dissemination materials (eg, press release and key findings documents). All these materials were produced in both English and French to increase their reach. ParticipACTION also hired a public relations agency that was in charge of posting the press release documents on a newswire, a day before the release of the concerned Report Card or Global Matrix and monitored the media hits and impressions generated by the release. In addition, ParticipACTION communication professionals also developed a social media strategy for the dissemination of the Report Card and Global Matrix information on Facebook, Twitter, and Instagram in both English and French.

\section{Online and Social Media Presence}

Other potential vectors of dissemination of the Global Matrices and country Report Cards' information to the general population and stakeholders are publicly available online via websites and social media platforms. Indeed, numerous countries Report Card working groups and institutions have created web pages, websites, and/or social media accounts, where they are able to share information and documents related to their country's Report Card and/or the Global Matrices with the public. Report Card leaders were asked to report websites and social media accounts in the Global Matrix 3.0 postlaunch survey. A total of 32 websites or web pages, 7 active Facebook accounts, 9 Twitter accounts, and 2 Instagram accounts were reported by the Report Card leaders. In addition, the AHKGA Twitter account (@activehealthykids.org), AHKGA LinkedIn page (www.linkedin.com/company/ahkga), and AHKGA website (www.activehealthykids.org) were created to communicate the AHKGA activities, the Global Matrices development, and relevant Global Matrix or Report Card news. A special web page for each country (eg, www.activehealthykids.org/australia) that has participated in any of the past Global Matrices is also available on the AHKGA website since the launch of Global Matrix 3.0, presenting all the available country Report Card documents and articles, Report Card leaders' testimonials, the top 3 strategies to improve the physical activity grades identified by the Report Card working groups, and any other relevant information a Report Card leader asked to be posted.

The AHKGA website was first created in 2015 to support the development of Global Matrix 2.0 and was then used for the dissemination of Global Matrix and Report Card-related information. Within the 3 months following the release of the Global Matrix 2.0, a total of 13,129 pages were visited by 4930 visitors. And, a total of 22,884 pages were visited by 6505 visitors during the 3 months after the launch of the Global Matrix 3.0. The observed increased use of the AHKGA website between Global Matrix 2.0 and Global Matrix 3.0 releases can potentially be explained by the greater number of participating countries in Global Matrix 3.0, but also the general augmentation of the use of Internet resources in the modern society over time. This finding shows that the AHKGA website is also a reliable source of dissemination of the Global Matrix and Report Card-related information to the population. 


\section{Impact on Powering the Movement to Get Kids Moving Nationally and Internationally}

Although the comparison of the physical activity grades over the 3 Global Matrices showed that it was still too early to observe a positive change in physical activity levels among children and youth, positive outcomes in terms of the promotion of physical activity have already been directly linked to the Global Matrix and Report Card initiatives.

A sample of success stories that were reported to the AHKGA by the Report Card leaders during the development and after the launch of the Global Matrix 3.0 are presented in Table 5. Numerous stories describe how the Global Matrix and the Report Card activities have helped to raise awareness, build capacity, increase government involvement, generate attention in the media, initiate new policies, provide positive outcomes in research, and improve surveillance. These samples are in addition to the selection previously presented in the Global Matrix 2.0 integrated article. ${ }^{16}$ These success stories show that participation in the Global Matrices, combined with efforts and initiatives of the Report Card working group members, has the potential to generate favorable outcomes with regard to the promotion of physical activity among children and youth. These success stories are organized in 8 categories in Table 5, an example from each category is developed in the following paragraphs.

The "awareness" category contains reports of how the national Report Card within a given country has contributed to increase interest in the child and youth physical inactivity issue, in particular at the government level. For example, at a 2018 National Assembly of Wales-Health, Social Care and Sport Committee meeting, the 2016 Welsh Report Card ${ }^{40}$ was mentioned, and the 2018 Report $\mathrm{Card}^{41}$ was included on the meeting agenda. The discussion of the Report Card provided evidence that increased cabinet minister's involvement in debates surrounding data and issues related to active healthy kids in Wales.

The "capacity building" category contains examples of how the Report Card development process or final product(s) have supported, or continue to support, the development of sustainable local resources that are relevant for physical activity promotion. The 2016 Colombia Report Card ${ }^{42}$ became part of the main source of information for the theory training of practitioners at the National Program of Healthy Lifestyles in Colombia. The Report Card allowed them to understand the current situation and importance of physical activity behaviors of children and youth and provided guidance to set goals for the program.

The "expanded Report Card" category reports cases where a country Report Card working group took the initiative to expand their Report Card in a way that goes beyond adding a few indicators. For instance, in The Netherlands, due to the success of the 2016 Dutch Report Card, a grant was received to develop the first ever "Physical Activity Report Card+" as a sequel to the Report Card. The Report Card+ reported evidence and grades about the 10 physical activity indicators, focusing on Dutch children with chronic conditions or disabilities. ${ }^{43}$

The "media impact" category provides examples of noticeable achievements that were generated by the release of a Report Card in terms of mainstream media mobilization. For example, because of the successful grades assigned to the physical activity indicators in the 2018 Slovenia Report Card, the Warner Bros Belgium is currently filming a documentary on physical activity in Slovenian schools.

The "national conference" category reports cases where a national conference was organized for or following the release of a Report Card, potentially generating media impact and raising awareness among stakeholders. On May 4, 2017, the Danish Report Card working group held a national conference entitled "Children, Youth and Movement: From Policy to Practice" based on the findings from their 2016 Report Card. ${ }^{44}$ The conference included several oral presentations by members of the Danish Report Card work group that were related to the various physical activity indicators included in the Report Card. About 100 individuals from research institutions, sports federations, municipalities, schools, organizations working with children, and government ministries attended this event. The conference received significant social media attention and Denmark's Report Card Leader gave interviews with local news media. In 2019, following the release of the Denmark 2018 Report Card, ${ }^{45}$ a new conference was held by the Danish Report Card working group to present updated findings on the 10 physical activity indicators.

The "policy" category lists cases where the Report Card development or release activities in a country facilitated discussion around the development of physical activity promotion policies between members of a Report Card working group and the government of a country. Following the publication of their first Report Card in 2016 showing that Chilean children and youth were among the least active of any country, ${ }^{46}$ Chile's Report Card working group assisted the government with the establishment of new regulations aiming to ensure that all children attending public schools are engaging in at least 1 hour of physical activity outside of physical education classes.

In the "research" category, examples of notable academic achievements, as well as cases where the Report Card or Global Matrix activities have generated the initiation of more scientific investigation are presented. For instance, an achievement that was noted by the AHKGA Board of Directors is that the Global Matrix 3.0 main article ${ }^{23}$ is currently used as the "go-to" reference for academics citing recent data concerning the global state of childhood physical activity and differences observed among countries.

Finally, cases where the Report Card development or release activities have facilitated the collection of new physical activity data in a country are listed in the "surveillance" category. In response to the first Report Card of China (2016), ${ }^{46}$ focusing only on data from Shanghai, the Chinese Report Card working group developed the PAFCTYS. The PAFCTYS is a national surveillance protocol that is conducted on a yearly basis to collect physical activity data from a nationally representative group of school children across the country. Data from the first cycle of PAFCTYS informed China's 2018 Report Card. ${ }^{35}$

After the release of the Global Matrix 2.0 in 2016, the Report Card leaders from 38 countries completed the post-launch survey, and $81 \%$ reported feeling that the Global Matrix 2.0 was contributing to an increase in scientific knowledge and to "powering the movement to get kids moving." A large majority (97\%) expected their Report Card to have a positive influence on "powering the movement to get kids moving" in their country: mostly by increasing public awareness (92\%), improving the ability to keep up with research in the field and identifying research gaps and surveillance needs (89\%), improving capacity for advocacy (75\%), forming partnerships (72\%), and creating policy/strategy development (64\%). Furthermore, $72 \%$ of the Report Card leaders thought that the Global Matrix 2.0 provided other benefits to society, mostly by helping raise awareness with parents and the general public and contributing to public health promotion on physical activity (19\%) and because it engages people at a global level for 
Table 5 Success Stories Reported to the AHKGA by the Report Card Leaders

\begin{tabular}{|c|c|c|}
\hline Category & Country & Description and link \\
\hline Awareness & Flanders (Belgium) & $\begin{array}{l}\text { Following the publication of the } 2018 \text { Flanders' Report Card, the Ministers for } \\
\text { Education and for Sport were called upon in the Parliament based on findings } \\
\text { reported in the Report Card. }\end{array}$ \\
\hline Awareness & United Arab Emirates & $\begin{array}{l}\text { The United Arab Emirates' inaugural Report Card has helped to raise awareness } \\
\text { about physical inactivity as a major public health issue in the country and region. } \\
\text { The Report Card and article can act as an excellent resource for any researchers/ } \\
\text { practitioners interested in the epidemiology of physical activity in the United } \\
\text { Arab Emirates. }\end{array}$ \\
\hline Awareness & Venezuela & $\begin{array}{l}\text { The Report Card leader was contacted by the Commission of Health of the National } \\
\text { Assembly of Venezuela to discuss nutrition and physical activity in Venezuelan } \\
\text { children. }\end{array}$ \\
\hline Awareness & Wales & $\begin{array}{l}\text { Active Healthy Kids Wales and the Welsh Report Cards have generated media } \\
\text { attention and the attention of the Welsh government and assembly members. }\end{array}$ \\
\hline Awareness & Wales & $\begin{array}{l}\text { At a } 2018 \text { National Assembly of Wales Health, Social Care and Sport Committee } \\
\text { meeting, the } 2016 \text { Welsh Report Card was mentioned, and the } 2018 \text { Report Card was } \\
\text { included on the meeting agenda. The discussion of the Report Cards provided } \\
\text { evidence that increased cabinet minister's involvement in debates surrounding data } \\
\text { and issues related to active healthy kids in Wales. }\end{array}$ \\
\hline Capacity building & Colombia & $\begin{array}{l}\text { The } 2016 \text { Colombia's Report Card became part of the main sources of information for } \\
\text { the training of practitioners at the National Program of Healthy Lifestyles in } \\
\text { Colombia. }\end{array}$ \\
\hline Capacity building & Ghana & $\begin{array}{l}\text { The development of the } 2018 \text { Ghana's Report Card allowed to involve and train } \\
\text { senior students in physical education and sport in data monitoring and surveillance. }\end{array}$ \\
\hline Expanded Report Card & Japan & $\begin{array}{l}\text { Japan's Report Card working group developed a Report Card detailing the grades for } \\
\text { the } 10 \text { physical activity indicators for each of the } 47 \text { Japanese prefectures. It means } \\
\text { that the equivalent of } 47 \text { "mini" Report Cards, one for each prefecture of Japan, were } \\
\text { developed and compiled in a final document, offering a detailed cartography of the } \\
\text { physical activity behaviors and sources of influence across Japan. }\end{array}$ \\
\hline Expanded Report Card & The Netherlands & $\begin{array}{l}\text { Due to the success of the } 2016 \text { Dutch Report Card, a grant was received to develop the } \\
\text { first ever Physical Activity Report Card+ as a sequel to the Report Card. The Report } \\
\text { Card+ reported about the movement achievements and sedentary behavior of Dutch } \\
\text { children with chronic conditions or disabilities. }\end{array}$ \\
\hline Media impact & Slovenia & $\begin{array}{l}\text { Feedback from Slovenia Report Card article coauthors was that this was an } \\
\text { exceptional project to be a part of and that there was more publicity for the Slovenian } \\
\text { school physical activity programs than anything that has taken place in the past } \\
\text { number of years. }\end{array}$ \\
\hline Media impact & Slovenia & $\begin{array}{l}\text { Because of the successful grades assigned to the physical activity indicators in the } \\
2018 \text { Slovenia's Report Card, the Warner Bros Belgium is filming a documentary on } \\
\text { physical activity in Slovenian schools. }\end{array}$ \\
\hline National conference & Australia & $\begin{array}{l}\text { A stakeholder engagement forum was held in Australia immediately after the Global } \\
\text { Matrix } 2.0 \text { release. }\end{array}$ \\
\hline National conference & Denmark & $\begin{array}{l}\text { In } 2017 \text {, the Danish Report Card working group held a national conference based on } \\
\text { the findings from their } 2016 \text { Report Card. The conference included presentations } \\
\text { related to the various physical activity indicators included in the Report Cards. About } \\
100 \text { individuals from research institutions, sports federations, municipalities, schools, } \\
\text { organizations working with children, and government ministries attended this event. } \\
\text { The conference received significant social media attention and Denmark's Report } \\
\text { Card Leader gave interviews with local news media. In 2019, following the release of } \\
\text { the Denmark } 2018 \text { Report Card, a new conference was held by the working group to } \\
\text { present updated findings on the } 10 \text { physical activity indicators. }\end{array}$ \\
\hline Policy & Chile & $\begin{array}{l}\text { Following the publication of their first Report Card in 2016, Chile's Report Card } \\
\text { working group assisted with the establishment of new regulations aiming to ensure } \\
\text { that all children attending public schools are engaging in at least } 1 \mathrm{~h} \text { of physical } \\
\text { activity outside of physical education classes. }\end{array}$ \\
\hline Policy & Ghana & $\begin{array}{l}\text { The Report Card working group was involved in the development of new policy } \\
\text { guidelines for physical education and sport. }\end{array}$ \\
\hline Research & Brazil & $\begin{array}{l}\text { The } 2018 \text { Brazil Report Card working group developed and published in a Brazilian } \\
\text { peer-review journal a systematic review for each physical activity indicator. The } \\
\text { working group found enough evidence to grade all the Report Card indicators for the } \\
\text { first time, illustrating the quality of the work of the team involved. }\end{array}$ \\
\hline
\end{tabular}


Table 5 (continued)

\begin{tabular}{lll}
\hline Category & Country & Description and link \\
\hline Research & Ukraine/Bulgaria & Independent development of Report Cards on the physical activity of children and \\
& youth by using a method similar to that used to develop the Global Matrix Report \\
& Cards.
\end{tabular}

Research Ghana

Research International

Research and Policy England, Scotland, Wales, and Northern Ireland (United Kingdom)

Research, Policy, and Surveillance

Chile

Surveillance

Botswana

Surveillance Bulgaria

Surveillance Chile

Surveillance China

Surveillance Colombia

Surveillance Czech Republic

$\begin{array}{ll}\text { Surveillance } & \text { Scotland }\end{array}$
The work from Ghana's Report Cards (2014, 2016, and 2018) supported the initiation of the study of barriers in implementing physical education in Ghanaian schools.

The Global Matrix 3.0 main article is being used as a reference for academics citing recent data concerning the global state of physical activity and differences observed among countries.

Findings from the previous Report Cards (2016 or 2018) that were developed in England, Scotland, Wales, and Northern Ireland were included in the surveillance and implementation documentation of the 2019 Updated UK Physical Activity Guidelines. An article highlighting the work of the AHKGA in this regard has been recently accepted for publication in the British Journal of Sports Medicine. ${ }^{39}$

Chile's Report Card working group has partnered with the Ministry of Health in order to collaborate on surveillance studies, national strategies for the promotion of physical activity, and the identification of multilevel factors affecting behaviors.

In response to a lack of objective physical activity data revealed by Botswana's 2018 Report Card, a project is being developed to collect national data on the 10 indicators included in the Report Cards. The project is generating significant interest and support from numerous sectors of youth sport and health promotion, which will potentially result in partnership and funding opportunities.

The Report Card is giving the Bulgarian Report Card working group the opportunity to advocate for the importance of quality and relevant data and for the development of a systematic surveillance system of physical activity. BG Be Active is a nongovernmental organization that is working in the field of health-enhancing physical activity promotion and that needs relevant information about target groups in order to develop strategies and secure funding for activities.

Based on advocacy and the results from Chile's 2018 Report Card, a national physical activity survey was developed to provide data on all of the physical activity indicators that are included in the Report Cards.

In response to Shanghai's (China) 2016 Report Card, the Chinese Report Card working group developed the Physical Activity and Fitness in China-The Youth Study (PAFCTYS) in 2016. PAFCTYS is a national surveillance protocol that is conducted on a yearly basis to collect physical activity data from a nationally representative group of school children across the country.

The first 2 versions of the Report Card in Colombia helped to identify research gaps in the national surveillance of physical activity. This helped to advocate for the inclusion of new components to assess physical activity among children in the latest version National Survey of Nutrition (2015), which is the main source of data on physical activity at the national level.

Following the release of its first Report Card, the Czech Republic Report Card working group is currently in discussion with the Ministry of Health about the possibility to launch a national physical activity surveillance system.

Discussions with the government survey teams about how to extract and interpret data in the national surveys revealed that there were some data that researchers were not aware of, which were not reported in the national survey reports. In addition, the way in which data are operationalized in the national surveys is not always logical and can lead to overestimation of physical activity levels.

Abbreviation: AHKGA indicates Active Healthy Kids Global Alliance.

international cooperation, the exchange of good practices, and global networking $(15 \%)$.

Similarly, in 2018, after the release of the Global Matrix 3.0, several Report Card leaders reported in the Global Matrix 3.0 postlaunch survey that they expected their participation in the Global Matrix and Report Card processes to improve their capacity for advocacy. The Report Card leader of Chile stated that the Global Matrix 3.0 article was “. . . very useful for advocacy purposes and to identify/propose new ideas for policies." and added that Chile's Report Card was ". . . a relevant tool for practitioners and school professionals as they get a very updated state of the art of the current situation in Chile. Lot of them are using the Report Card to justify local proposals and programs along Chile." Most of the Report Card leaders $(41,84 \%)$ also declared that they expected their Report Card to have a positive influence on powering the movement to get kids moving in their country by raising awareness and $25(51 \%)$ by creating policy and strategy development.

"I think the Global Matrix 3.0 demonstrates how 49 countries that are very different in many respects can work together as one team composed of individual country teams to raise awareness and 
propose solutions for a shared global health problem: physical inactivity. A similar organizational framework could be used for other global public health issues" reported the leader of the Lebanon Report Card.

Overall, an overwhelming compilation of positive messages and feedback were reported by the Report Card leaders relative to their participation in the Global Matrix 3.0. More materials and analysis related specifically to the Global Matrix 3.0 process, development, release, and impact will be available in a Global Matrix 3.0 evaluation article (Aubert et al, under review in the Journal of Exercise Science \& Fitness).

\section{Summary of Impact}

Although it is still too early to observe a positive change in physical activity levels in children and youth, the Report Cards and Global Matrix initiative have had demonstrable impacts on powering the movement to get kids moving at both national and international levels. The evaluation of various sources of information shows an accumulation of evidence that the immediate and intermediate outcomes presented in the logic model of AHKGA (Figure 2) are already starting to be addressed. An impact on raising awareness and capacity building in the national and international scientific community, disseminating information to the general population and stakeholders, and finally on powering the movement to get kids moving has been observed. It is hoped that continuing to pursue the Global Matrix and Report Card activities will initiate a measurable shift in the physical activity levels of children and contribute to achieving the 4 strategic objectives of the World Health Organization Global Action Plan as follows: creating an active society, creating active environments, creating active lives, and creating active systems. ${ }^{22}$

\section{Strengths and Limitations}

This is the first article to summarize the international impact of the Global Matrices and Report Cards with a common goal to power the movement to get children and youth moving. This impact assessment was performed using a variety of both quantitative and qualitative sources of information, including surveys, peerreviewed publications, e-mails, gray literature among other sources. The main limitation of this impact assessment is that it relies partly on the reports made by the Report Card leaders, the Report Card team members, the mentors, and the AHKGA Board members. Consequently, the results may be biased and/or incomplete, making countries that reported more detailed information to the AHKGA look more successful than others. However, the qualitative information collected from Report Card leaders provides insight into the experiences had by Report Card working groups and leaders.

\section{Future Directions for the AHKGA Report Card and Global Matrices}

The AHKGA will pursue its journey to power the movement to get kids moving through the development of future Global Matrices on physical activity for children and youth and parallel activities. Future goals of the AHKGA include the following:

(1) Based on the model used in Canada, boost the impact of Report Cards and Global Matrix in other participating country's media. More efforts will also be made to improve the dissemination of the Report Card and Global Matrix findings through social media outlets at national, regional, and global levels.

(2) Recruit more countries to participate in the Global Matrices to cover the missing and underrepresented geographic areas, including the South Pacific, Northern and Central Africa, and Northern Asia.

(3) Contribute to the development and international adoption of standardized methods of evaluation of the Report Card indicators that are suitable and adjustable to all cultural contexts and all children and youth.

(4) Following the example of The Netherlands Report Card+ initiative, ${ }^{43}$ the AHKGA aims to include the evaluation of the physical activity indicator for children and youth with a disability or chronic disease.

(5) Following the examples of the Canadian and Polish Report Cards, where ParticipACTION and V4SPORT Foundation, respectively, are leading in the preparation of the Report Cards with working groups of national physical activity experts, the AHKGA wants to encourage Report Card leaders to create partnerships with local grassroots physical activity/ sport organizations to bridge the gap between what the scientific world knows and what active-healthy lifestyle organizations do.

(6) Develop a new financial system, so the functioning of the organization and its activities will not rely solely on the registration fees of the countries participating in the Global Matrices through fundraising, partnerships, sponsorships, and parallel activities.

\section{Acknowledgments}

The authors would like to express their sincere gratitude to the Report Card leaders from all countries that participated in the Global Matrix initiatives as well as those who served on their respective Report Card working groups. They are especially thankful to Dr Areekul Amornsriwatanakul for her participation on the AHKGA Executive Committee.

\section{References}

1. World Health Organization. Mortality and Burden of Disease Attributable to Selected Major Risks. 2009:70. https://www.who.int/ healthinfo/global_burden_disease/GlobalHealthRisks_report_full.pdf. Accessed April 4, 2018.

2. Lee IM, Shiroma EJ, Lobelo F, Puska P, Blair SN, Katzmarzyk PT. Effect of physical inactivity on major non-communicable diseases worldwide: an analysis of burden of disease and life expectancy. Lancet. 2012;380(9838):219-229. PubMed ID: 22818936 doi:10. 1016/S0140-6736(12)61031-9

3. Blair SN. Physical inactivity: the biggest public health problem of the 21st century. Br J Sports Med. 2009;43(1):1-2. PubMed ID: 19136507

4. Trost SG, Blair SN, Khan KM. Physical inactivity remains the greatest public health problem of the 21 st century: evidence, improved methods and solutions using the "7 investments that work" as a framework. Br J Sports Med. 2014;48(3):169-170. PubMed ID: 24415409 doi:10. 1136/bjsports-2013-093372.

5. Guthold R, Stevens GA, Riley LM, Bull FC. Worldwide trends in insufficient physical activity from 2001 to 2016: a pooled analysis of 358 population-based surveys with 1.9 million participants. Lancet Glob Health. 2018;6(10):e1077-e1086. doi:10.1016/S2214-109X (18)30357-7 
6. Sallis JF, Bull F, Guthold R, et al. Progress in physical activity over the Olympic quadrennium. Lancet. 2016;388(10051):1325-1336. PubMed ID: 27475270 doi:10.1016/S0140-6736(16)30581-5

7. Telama R, Yang X, Viikari J, Välimäki I, Wanne O, Raitakari O. Physical activity from childhood to adulthood: a 21-year tracking study. Am J Prev Med. 2005;28(3):267-273. PubMed ID: 15766614 doi:10.1016/J.AMEPRE.2004.12.003

8. Tomkinson GR, Olds TS. Secular changes in pediatric aerobic fitness test performance: the global picture. Med Sport Sci. 2007;50:46-66. PubMed ID: 17387251 doi:10.1159/000101075

9. Abarca-Gómez L, Abdeen ZA, Hamid ZA, et al. Worldwide trends in body-mass index, underweight, overweight, and obesity from 1975 to 2016: a pooled analysis of 2416 population-based measurement studies in 128.9 million children, adolescents, and adults. Lancet. 2017;390(10113):2627-2642. doi:10.1016/S0140-6736(17)32129-3

10. Lobstein T, Baur L, Uauy R. Obesity in children and young people: a crisis in public health. Obes Rev. 2004;5(s1):4-85. doi:10.1111/j. 1467-789X.2004.00133.x

11. Tremblay MS, Gray CE, Akinroye K, et al. Physical activity of children: a global matrix of grades comparing 15 countries. J Phys Act Health. 2014;11(s1):S113-S125. doi:10.1123/jpah.2014-0177

12. Colley RC, Brownrigg M, Tremblay MS. A model of knowledge translation in health. Health Promot Pract. 2012;13(3):320-330. PubMed ID: 22447666 doi:10.1177/1524839911432929

13. Tremblay MS, Barnes JD, Bonne JC. Impact of the active healthy kids Canada report card: a 10-year analysis. J Phys Act Health. 2014; 11(s1):S3-S20. doi:10.1123/jpah.2014-0167

14. Barnes JD, Tremblay MS. Changes in indicators of child and youth physical activity in Canada, 2005-2016. Can J Public Health. 2017;107(6):586. doi:10.17269/cjph.107.5645

15. Tremblay MS. 2014 global summit on the physical activity of children. J Phys Act Health. 2014;11(S1):S1-S2. doi:10.1123/jpah. 2014-0182

16. Tremblay MS, Barnes JD, González SA, et al. Global matrix 2.0: report card grades on the physical activity of children and youth comparing 38 countries. J Phys Act Health. 2016;13(11)(suppl 2): S343-S366. doi:10.1123/jpah.2016-0594

17. United Nations. A/66/83 - E - Prevention and Control of Non-Communicable Diseases, Report of the Secretary-General. New York: United Nations; 2011. https://undocs.org/en/A/66/83. Accessed August 29, 2018.

18. World Health Organization. Global Action Plan for the Prevention and Control of Noncommunicable Diseases : 2013-2020. Geneva, Switzerland: World Health Organization; 2013. http://apps.who. int/iris/bitstream/handle/10665/94384/9789241506236_eng.pdf? sequence=1. Accessed April 5, 2018.

19. United Nations. Transforming Our World: The 2030 Agenda for Sustainable Development: Sustainable Development Knowledge Platform. New York: United Nations; 2015. https://sustainabledevelopment. un.org/post2015/transformingourworld. Accessed April 5, 2018.

20. ISPAH. The Bangkok Declaration on Physical Activity for Global Health and Sustainable Development. Bangkok: ISPHA; 2016:4. http://api.ning.com/files/V0BiFi-tkRtNBOh-2povpLXSGLAazPBz8 KItEppPYDz4TzYQ7jUGub6GuuiAdXPIdA6lbCgjeugQswM4vqlp AhOji36u5xE9/BKK_Declaration_Final_2016.pdf. Accessed April 5, 2018.

21. World Health Organization. Report of the Commission on Ending Childhood Obesity. Geneva, Switzerland: World Health Organization; 2016. http://apps.who.int/iris/bitstream/handle/10665/ 204176/9789241510066_eng.pdf?sequence=1. Accessed April 5, 2018.

22. World Health Organization. Global Action Plan on Physical Activity 2018-2030. Geneva, Switzerland: World Health Organization;
2018:1-101. http://apps.who.int/iris/bitstream/handle/10665/272722/ 9789241514187-eng.pdf?ua=1. Accessed August 30, 2018.

23. Aubert S, Barnes JD, Abdeta C, et al. Global Matrix 3.0 physical activity report card grades for children and youth: results and analysis from 49 countries. J Phys Act Health. 2018;15(S2):S251-S273. PubMed ID: 30475137 doi:10.1123/jpah.2018-0472

24. Active Healthy Kids Global Alliance. About Us: Active Healthy Kids Global Alliance. 2018. https://www.activehealthykids.org/about/. Accessed January 31, 2019.

25. United Nations. Political Declaration of the UN High-Level Meeting on the Prevention and Control of Non-Communicable Diseases (NCDs): Key Points Background. New York: United Nations; 2012. https://ncdalliance.org/sites/default/files/rfiles/ KeyPointsofPoliticalDeclaration.pdf. Accessed April 5, 2018.

26. Global Advocacy for Physical Activity. Toronto Charter for Physical Activity. http://www.globalpa.org.uk/charter/. Accessed August 29, 2018.

27. Bull FC, Gauvin L, Bauman A, Shilton T, Kohl HW, Salmon A. The Toronto charter for physical activity: a global call for action. $J$ Phys Act Health. 2010;7:421-422. https://pdfs.semanticscholar.org/4b34/ 24f9139dbf473ac035737ca53ac94c633639.pdf. Accessed April 5, 2018.

28. Draper CE, Tomaz SA, Bassett SH, et al. Results from South Africa's 2018 Report Card on physical activity for children and youth. $J$ Phys Act Health. 2018;15(S2):S406-S408. PubMed ID: 30475151 doi:10. 1123/jpah.2018-0517

29. Uys M, Bassett S, Draper CE, Micklesfield L, Monyeki A, De Villiers A. Results from South Africa's 2016 Report Card on physical activity for children and youth. J Phys Act Health. 2016;13(S2):265-273. doi:10.1123/jpah.2016-0409

30. Draper C, Basset S, De Villiers A, Lambert EV. Results from South Africa's 2014 report card on physical activity for children and youth. J Phys Act Health. 2014;11(S1):S98-S104. doi:10.1123/jpah. 2014-0185

31. Galaviz KI, Argumedo Garcia G, Gaytán-González A, et al. Results from Mexico's 2018 report card on physical activity for children and youth. J Phys Act Health. 2018;15(S2):S384-S385. PubMed ID: 30475116 doi:10.1123/jpah.2018-0462

32. López y Taylor JR. The Mexican Report Card on Physical Activity for Children and Youth-Short Form. Guadalajara, Mexico: CAMBIO program; 2012.

33. Galaviz KI, Arroyo MA, González-Casanova I, et al. Results From Mexico's 2016 report card on physical activity for children and youth. J Phys Act Health. 2016;13(11)(suppl 2):S206-S212. doi:10.1123/ jpah.2016-0363

34. Amornsriwatanakul A, Nakornkhet K, Katewongsa P, et al. Results from Thailand's 2016 report card on physical activity for children and youth. J Phys Act Health. 2016;13(11)(suppl 2):S291-S298. doi:10. 1123/jpah.2016-0316

35. Liu Y, Tang Y, Cao Z-B, et al. Results from China's 2018 report card on physical activity for children and youth. J Phys Act Health. 2018;15(S2):S333-S334. PubMed ID: 30475103 doi:10.1123/jpah. 2018-0455

36. Instituto Colombiano de Bienestar Familiar ICBF. Encuesta Nacional de la Situación Nutricional en Colombia ENSIN 2015. Bogotá D.C; 2018.

37. Gustafson SL, Rhodes RE. Parental correlates of physical activity in children and early adolescents. Sport Med. 2006;36(1):79-97. doi:10. 2165/00007256-200636010-00006

38. Sallis JF, Prochaska JJ, Taylor WC. A review of correlates of physical activity of children and adolescents. Med Sci Sports Exerc. 2000; 32:963-975. http://www.msse.org. Accessed April 2, 2019.

39. Strain T, Milton K, Dall P, et al. How are we measuring physical activity and sedentary behaviour in the four home nations of the UK? 
A narrative review of current surveillance measures and future directions [published online May 22, 2019]. Br J Sports Med. 2019; doi:10.1136/bjsports-2018-100355

40. Tyler R, Mannello M, Mattingley R, et al. Results from Wales' 2016 report card on physical activity for children and youth: Is Wales turning the tide on children's inactivity? J Phys Act Health. 2016;13(11, suppl 2):S330-S336. doi:10.1123/jpah.2016-0309

41. Edwards LC, Tyler R, Blain D, et al. Results from Wales' 2018 report card on physical activity for children and youth. J Phys Act Health. 2018;15(S2):S430-S432. PubMed ID: 30475120 doi:10.1123/jpah. 2018-0544

42. González SA, Castiblanco MA, Arias-Gómez LF, et al. Results from Colombia's 2016 report card on physical activity for children and youth. J Phys Act Health. 2016;13(11)(suppl 2):S129-S136. doi:10. 1123/jpah.2016-0369

43. Burghard M, de Jong NB, Vlieger S, Takken T. 2017 Dutch report card $^{+}$: results from the first physical activity report card plus for Dutch
Youth with a chronic disease or disability. Front Pediatr. 2018;6:122. PubMed ID: 29761094 doi:10.3389/fped.2018.00122

44. Larsen LR, Troelsen J, Kirkegaard KL, et al. Results from Denmark's 2016 report card on physical activity for children and youth. $J$ Phys Act Health. 2016;13(11)(suppl 2):S137-S142. doi:10.1123/jpah. 2016-0403

45. Nørager Johansen DL, Neerfeldt Christensen BF, Fester M, et al. Results from Denmark's 2018 report card on physical activity for children and youth. J Phys Act Health. 2018;15(S2):S341-S343. doi:10.1123/jpah.2018-0509

46. Aguilar-Farias N, Cortinez-O'Ryan A, Sadarangani KP, et al. Results from Chile's 2016 report card on physical activity for children and youth. J Phys Act Health. 2016;13(11)(suppl 2):S117-S123. doi:10. 1123/jpah.2016-0314

47. Liu Y, Tang Y, Cao Z-B, et al. Results from Shanghai's (China) 2016 report card on physical activity for children and youth. J Phys Act Health. 2016;13(11)(suppl 2):S124-S128. doi:10.1123/jpah.2016-0362 